turer sells his product to the retailer, the manufacturer's interest ends, and who, therefore, deny the justice of permitting the manufacturer to fix the resale price, might well weigh this question which a speaker recently asked his audience:

Suppose a retailer had his choice of having the Ivory soap people supply him with a case of unmarked cakes, in plain white wrappers, or having the soap delivered with the trade-mark affixed, as usual,-which soap would he prefer?

The answer is obvious, of course.

Why would the retailer prefer the soap bearing the maker's mark? Isn't it because the manufacturer sells the retailer more than mere soap? Isn't it because the maker hands over to the retailer an existing market, along with the goods to satisfy that market?

Isn't it the business of the manufacturer, in the interest of his own business, in the interest of other retailers to whom he is also delivering the existing market along with the soap, and on behalf of the public, to do what he can to keep that market from being destroyed?

The manufacturer could not be expected to stand aside and allow a retailer to change the soap in such a manner as to reduce its usefulness; and must he be compelled to allow that other asset, the existing market, to be injured? Is it not as proper for him to look after the preservation of the one asset as the other?

Most of the sincere opposition to price maintenance legislation has been based either upon the fear that the law would be technically in- correct, or upon fallacious logic. The idea that a manufacturer would fix an unreasonable price, then blow his good money for advertising is too ridiculous to be considered. He would not spend good money making a market for some other fellow to supply?

\section{SPECIAL FORMULA APPROVED FOR DENATURING ALCOHOL FOR TINCTURE OF IODINE.}

The following formula, designated as No. 25, has been approved by the Commissioner of Internal Revenue for the special denaturation of alcohol to be used exclusively in the manufacture of the tincture of iodine:

"To every roo wine gallons, by volume, of ethyl alcohol of not less than 180 degrees proof, there shall be added twenty pounds by weight, of iodine, such alcohol when so denatured to be used exclusively in the manufacture of tincture of iodine, in accordance with the requirements of the United States Pharmacopoeia."

This formula cannot be used in central denaturing bonded warehouses or distillery denaturing bonded warehouses, but the use thereof is authorized for the denaturation of alcohol in central distilling and denaturing plants, the same being one of the two classes of industrial distilleries established under Subsection 2, of Paragraph $\mathbf{N}$ of Section 4, act of October 3, 1913 , and Supplement No. 2 to Regulations 30.

Permission must be obtained to use a special denaturant in any central distilling and denaturing plant, as provided in Articles 2 and $r g$ of the supplement.

\title{
CHANGES OF ADDRESS.
}

All changes of address of members should be sent to the General Secretary promptly.

The Association will not be responsible for non-delivery of the Annual Volume or Year Book, or of the JouRNAL unless notice of change of address is received before shipment or mailing.

Both the old and the new address should be given thus:

$$
\begin{aligned}
& \text { HENRY MilTon, } \\
& \text { From } 2342 \text { Albion Place, St. Louis, Mo. } \\
& \text { To } 278 \text { Dartmouth St., Boston, Mass. }
\end{aligned}
$$

Titles or degrees to be used in publications or in the official records should be given, and names should be plainly written, or typewritten.

\section{CHANGE OF ADDRESS SINCE NOVEMBER I 8, I9I6.}

HE'ss, J. L.,

From 2038 Cherry St., Philadelphia, Pa.

To I 10 N. Second St., Millville, N. J.

FENDER, W. E.,

From Fort Monroe, Va.

To Camp Hosp., Laredo, Texas.
LAKAMP, W., From 1201 Vine St., Cincinnati, Ohio.

To The Georgian Flats, Madison Rd. \& Paul, Cincinnati, Ohio.

Hommann, Geo.,

From 75 I Courtland Ave., New York, N. Y.

To 2480 Concourse St., New York, N. Y. 
SPEASE, ED.,

From $89 \mathrm{E}$. Norwich Ave., Columbus, Ohio. To roor I No. Blvd., Cleveland, Ohio.

GADDY, R. L.,

From Dillon, S. C.

To Greenville, S. C.

GIDLEY, WM. F.,

From 220 Sylvia St., W. Lafayette, Ind.

To I 23 Russell, W. Lafayette, Ind.

SHNITTER, A.,

From 1230 Boston Rd., New York, N. Y. To 804 E. I 78 th St., New York, N. Y.

Groom, J. I,

From W. Lafayette, Ind.

To Shelbyville, Ind.
BOXER, B.

From 1412 Washington Ave., Bronx, New York, N. Y.

To 2023 Washington Ave, Bronx, New York, N. $\mathbf{Y}$.

FAss, S. M.,

From I I 2 Delencey St., New York, N. Y.

To I076 Teller Ave., Bronx, New York, N. Y.

SCHLOTTERBECK, J. O.,

From 907 Lincoln Ave., Ann Arbor, Mich.

To $\%$ Chemical Laboratory, Univ. of Mich., Ann Arbor, Mich.

DECEASED SINCE NOVEMBER I8, I 916 .

WiLBERT, M. I., Washington, D. C.

\section{BOOK NOTICES AND REVIEWS.}

The National Standard Dispensatory. Hobart Amory Hare, B.Sc., M.D., Charles Caspari, Jr., Ph.G., Phar.D., Henry H. Rusby, M.D. Third edition, enlarged and thoroughly revised. Publishers: Lea \& Febiger, Philadelphia and New York.

The Ninth Decennial Revision of the Pharmacopoeia of the United States and the recent revisions of the German, French and English Pharmacopoeias necessitated a revised edition of this commentary. The intent of the authors, as set forth in their preface, is to present in this single volume "encyclopaedic information concerning all substances used in pharmacy and medicine at the present day." In the publishers' note the reader is likewise assured that "the aim has been to make the National Standard Dispensatory a reference work of the highest authority upon the entire range of Materia Medica, Pharmacy, and Therapeutics,"

These are most laudable purposes, and it is with sincere regret that a critical review from the view-point of a pharmacist, who esteemed the good points of its predecessor The National Dispensatory and always admired the exactness of knowledge pharmaceutical, chemical and pharmacognostical displayed by his teacher and friend the late John M. Maisch, does not permit of the conclusion that these have been attained in the present edition. As this review is purely pharmaceutical no comments, whatever, on the therapeutics are submitted, and it is the hope that, in that respect, the work may well serve the purpose of the authors.

With the possible exceptions of binding, prefatory pages and index, the U. S. P. IX is embodied practically in its entirety in this revised work and even the lists and tables of the Pharmacopoeia are incorporated. One is somewhat at a loss to understand why in a modern work statements of temperature, weight, volume or dimension must be followed by bracketted equivalents; as examples: " 25 " C. ( $77^{\circ}$ F.)," "Io to 20 grains ( 0.60 to 1.30 Gm.)," "20 minims ( 1.3 mils.)," "25 mm. (0.98 In.)." "12 Cm. (5 In.)." Since the official tables of equivalents have been republished in the volume, this appears to be useless.

We note that the pharmacopoeial adoption of "mil" as a distinct noun has not been accepted and throughout it is used as an abbreviation, thus "Mil." and "Mils." The pharmacopoeial chemical formulas are quite frequently not followed and the official order of stating the elements is not observed. It should not be necessary to add after HCN "old style HCY." Specific gravities are generally stated at $15^{\circ} \mathrm{C}$. instead of at the temperature officially adopted $25^{\circ} \mathrm{C}$; at times, these are given at both temperatures.

If the use of the metric system of weights and measures is ever to become the common practice in America, the commentaries must cease to transpose official formulas and statements into the denominations of the apothecaries' system. In the volume before us, this has been persisted in throughout and can be viewed only as another discouragement of, and postponement of, the adoption of the metric system.

The treatment of the botanical and pharmacognostical subjects is concise, accurate and commendably practical, Botanical descrip- 